\title{
DENSITY AND FLOCK SIZE OF THE RAVEN (Corvus corax) IN THE ORAWA - NOWY TARG BASIN DURING NON-BREEDING SEASON
}

\author{
Michał Ciach, Dominik Wikar and Małgorzata Bylicka
}

\begin{abstract}
Ciach M., Wikar D., Bylicka M., 2006. Density and flock size of the Raven (Corvus corax) in the Orawa - Nowy Targ Basin during non-breeding season. Ring 28, 2: 119-125.

During the 2002/2003-2004/2005 non-breeding seasons the density of the Raven in the open habitats of the Orawa - Nowy Targ Basin was studied by line transect method. The results were analysed in four periods (autumn, early winter, winter and early spring). The median density of Ravens did not differ significantly between individual periods and was respectively: 3.5, 3.8, 4.8 and 3.8 indiv. / $10 \mathrm{~km}$. Number of birds during particular controls varied from 1.0 to $24.8 \mathrm{indiv}$. / $10 \mathrm{~km}$. However, while excluding flocks, the median density of single individuals and pairs of the Raven was considerably lower and in subsequent periods reached respectively: 2.2, 2.4, 2.2 and 1.7 indiv. / $10 \mathrm{~km}$. Flock size did not differ significantly between individual periods. Single individuals and, less often, groups of two birds were recorded mostly. Small (3-5 indiv.) and medium (6-15 indiv.) flocks were recorded rarely and large flocks (16 indiv. and above) - only exceptionally. The high density and strong fluctuations of abundance of Ravens were determined by flocks presence, which was probably linked to irregular occurrence of food resources.
\end{abstract}

M. Ciach (corresponding author), D. Wikar, M. Bylicka, Dept. of Forest Zoology and Wildlife Management, Agricultural University of Kraków, Faculty of Forestry, Al. 29 Listopada 46, PL-31-425 Kraków, Poland, E-mail: mciach@ar.krakow.pl

Key words: Common Raven, Corvus corax, density, flock size, non-breeding season, Orawa Nowy Targ Basin, southern Poland, Carpathians.

\section{INTRODUCTION}

European population of the Raven is considered to be mainly resident, undertaking short-distance nomadic movements only (Busse 1969). In Poland, the number of breeding pairs and wintering birds has increased for recent decades (Tomiałojć and Stawarczyk 2003). During 1984-1993, number of wintering Ravens in central-eastern Poland increased threefold (Jędrzejewski 2000). Regular use of rubbish-dumps by non-breeding Ravens has occurred recently (Mošanský and 
Karaska 2002, Betleja and Meissner 2005). Birds also concentrate close to animal carcasses dumps (Jermaczek et al. 1995, Bednorz 2000).

Biology and ecology of the Raven in Poland, especially in non-breeding season, are poorly known (Bednorz 2005). There are shortages of knowledge of Ravens' non-breeding density, inter- and intra-seasonal abundance fluctuation, flock characteristics and food composition. These concern particularly populations from mountainous and foothills terrain. The aim of this paper is to determine the density and flock structure of the Raven during non-breeding season in the mountain valley.

\section{STUDY AREA}

The Orawa - Nowy Targ Basin covers the area of $370 \mathrm{~km}^{2}$ at 500-600 m a.s.l. and borders with the Beskidy Zachodnie mountain ranges (Kondracki 1998). It is covered by mosaic of diverse biotopes. Numerous afforestation, forests, peat bogs and open farmlands are crossed with streams, routes and built-up areas. The climate of the Orawa - Nowy Targ Basin is harsh. It is noted for being continental and it differs from neighbouring mountain chains (Konček 1974). Observations were conducted in three established transects with a total length of $31.5 \mathrm{~km}$ located in open areas between Czarny Dunajec ( $\left.49^{\circ} 44^{\prime} \mathrm{N}, 19^{\circ} 85^{\prime} \mathrm{E}\right)$, Piekielnik $\left(49^{\circ} 47^{\prime} \mathrm{N}, 19^{\circ} 76^{\prime} \mathrm{E}\right)$ and Ludźmierz $\left(49^{\circ} 46^{\prime} \mathrm{N}, 19^{\circ} 97^{\prime} \mathrm{E}\right)$. Details of transects description and full characteristic of study area are given elsewhere (Ciach et al. 2006).

\section{METHODS}

Research was carried out from October to March during the 2002/2003 -2004/2005 seasons (during the first season - from the end of November). Marked transects were surveyed in the middle and at the end of every month. Birds were counted within the range of vision, which extended from 200 to $1000 \mathrm{~m}$ on each side of the transect and was limited by characteristic objects (clump of trees, forests, routes, buildings) and the topography of the terrain. All the transects were surveyed on the same day with the speed of $2-3 \mathrm{~km} / \mathrm{h}$. The flock size and presence of other corvids in the flock were recorded. The length of transects was established by using GPS. Bird density was calculated per $10 \mathrm{~km}$ of transect.

The Ravens groups characteristic is based on single-species groups only. Relative values were used to show fluctuation of abundance, they were calculated by using formula:

$$
L_{r}=\frac{N \times 100 \%}{N_{m n}}
$$

where:

$L_{r}$ - relative value of abundance,

$N$ - number of birds recorded in a given control,

$N_{m n}$ - mean abundance in a given season. 
Controls were classified into four periods (Table 1), divided based on meteorological data (Konček 1974). Weather conditions recorded in subsequent study seasons were similar to each other and corresponded to given periods.

Table 1

Characteristic differences in periods according to Konček (1974) and the numbers of surveys.

\begin{tabular}{|l|c|c|c|c|}
\hline \multicolumn{1}{|c|}{ Period } & Autumn & Early winter & Winter & Early spring \\
\hline Dates & 25 Sep.-22 Nov. & 23 Nov.-25 Dec. & 26 Dec.-18 Mar. & 19 Mar.-12 Apr. \\
\hline Number of days & 59 & 33 & 84 & 24 \\
\hline Temperature & $0^{\circ}-10^{\circ} \mathrm{C}$ & $<0^{\circ} \mathrm{C}$ & $<0^{\circ} \mathrm{C}$ & $0^{\circ}-5^{\circ} \mathrm{C}$ \\
\hline Extended snow cover & none & none & 26 Dec.-18 Mar. & none \\
\hline Number of controls & 7 & 6 & 17 & 4 \\
\hline
\end{tabular}

\section{RESULTS}

Median density of Ravens in the Orawa - Nowy Targ Basin did not differ significantly between periods (Kruskal-Wallis test: $H=1.05, p=0.79$; Fig. 1 ). However, range of density in each period was considerable. Number of birds between subsequent surveys considerably fluctuated (Fig. 2). Median density in autumn was 3.5 indiv. / $10 \mathrm{~km}$ (1.0 to 16.2 indiv. / $10 \mathrm{~km})$, in early winter -3.8 indiv. / $10 \mathrm{~km}(1.0$ to 12.7 indiv. / $10 \mathrm{~km})$, in winter -4.8 indiv. / $10 \mathrm{~km}$ (1.0 indiv. / $10 \mathrm{~km}$ to 24.8 indiv. / $10 \mathrm{~km})$ and in early spring -3.8 indiv. / $10 \mathrm{~km}(2.2$ to 15.2 indiv. / $10 \mathrm{~km})$. High density of the species was strongly determined by the presence of flocks of three and above individuals. Density of single individuals and groups of two birds only was signifi-

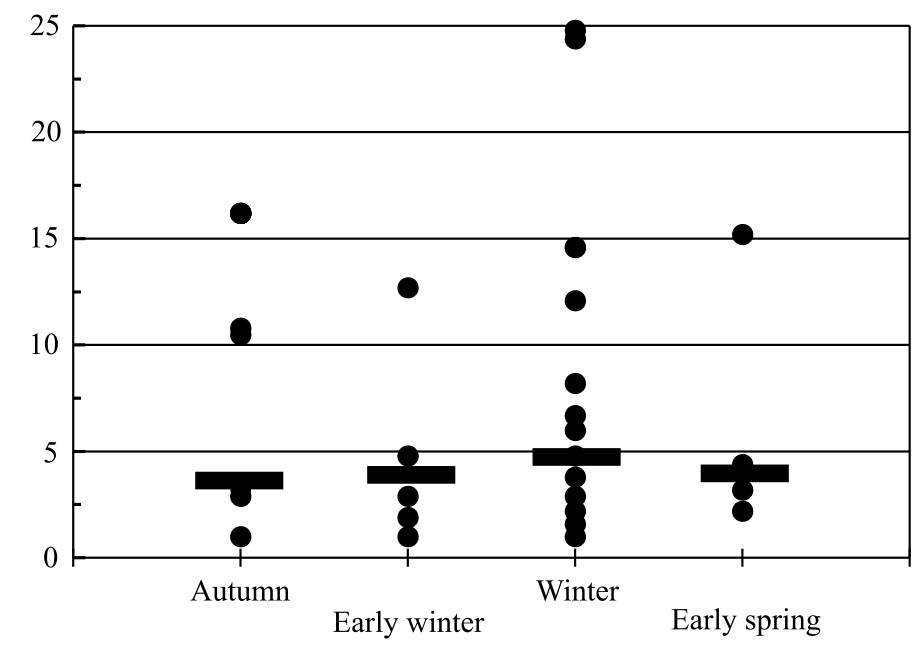

Fig. 1. Density (indiv. / $10 \mathrm{~km}$ ) of Ravens within subsequent periods in the Orawa - Nowy Targ Basin during 2002/2003-2004/2005 non-breeding seasons. Medians are given as horizontal bars. 

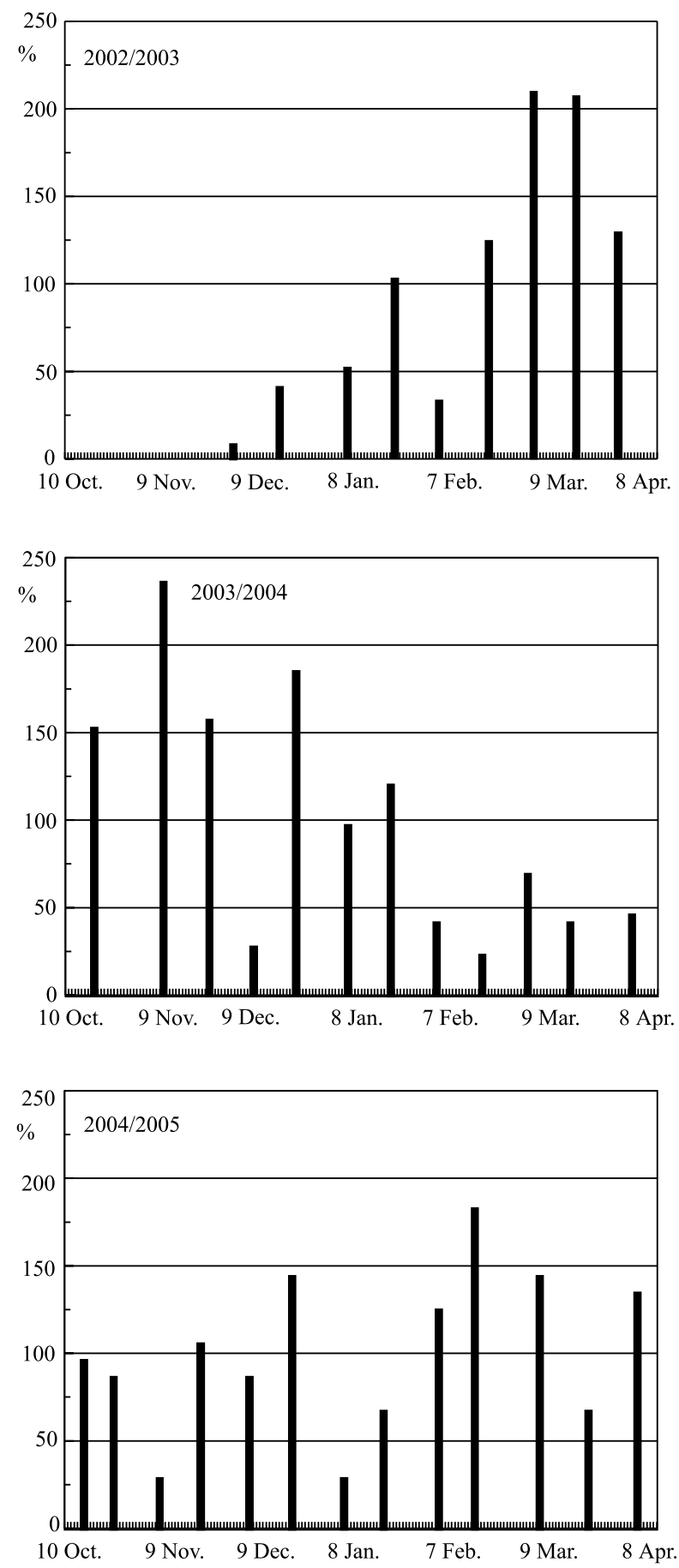

Fig. 2. Abundance fluctuations of the Raven in the Orawa - Nowy Targ Basin during non-breeding seasons of 2002/2003-2004/2005 (relative values of bird numbers shown as percentages of mean abundance in a given season) 
cantly lower than density of all recorded types of groups (Wilcoxon test: $Z=4.46$, $p<0.001$ ). It was stable (Kruskal-Wallis test: $H=1.63, p=0.65$ ) and in subsequent periods its median value was respectively: 2.2, 2.4, 2.2 and 1.7 indiv. / $10 \mathrm{~km}$ (Fig. 3). In subsequent seasons a decrease in median density was recorded (Kruskal-Wallis test: $H=7.73, p<0.05)$. In 2002/2003 season the median density was 12.1 indiv. / 10 $\mathrm{km}$, in 2003/2004 - 5.7 indiv. / $10 \mathrm{~km}$ and in 2004/2005 - 2.9 indiv. / $10 \mathrm{~km}$.

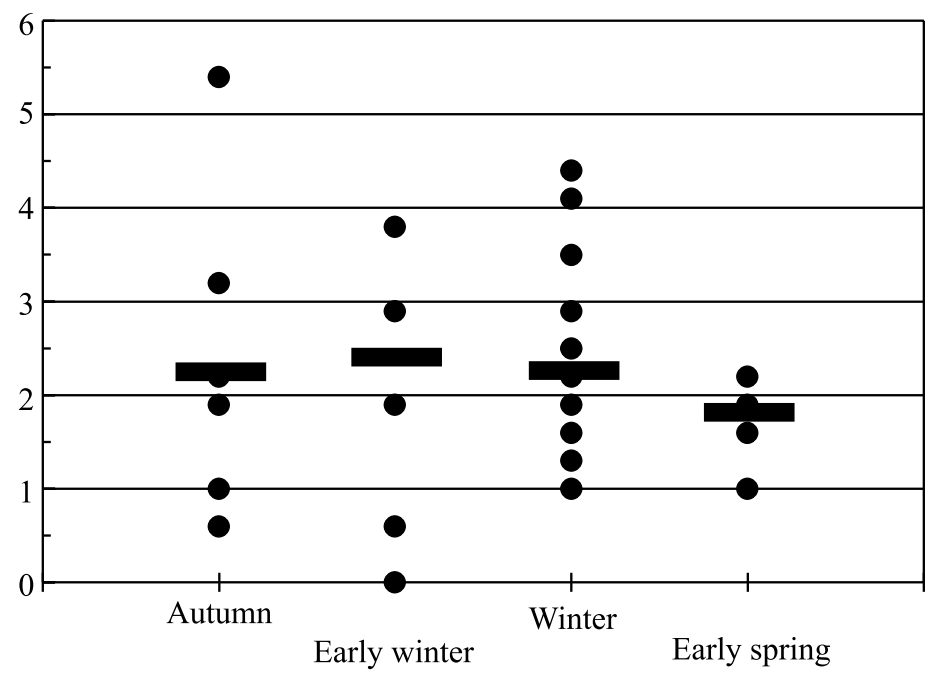

Fig. 3. Density (indiv. / $10 \mathrm{~km}$ ) of single individuals and pairs of the Raven within subsequent periods in the Orawa - Nowy Targ Basin during 2002/2003-2004/2005 non-breeding seasons. Medians are given as horizontal bars.

Single Ravens and, less often, groups of two predominated (Table 2). Only during winter both were recorded with similar frequency. Together they constituted 74-82\% of recorded groups in individual periods. In all meteorological periods the presence of small (3-5 birds) and medium (6-15 birds) flocks were recorded. Larger flocks were recorded exceptionally. No differences in flock size between individual periods were recorded (Kruskal-Wallis test: $H=1.36, n s$ ). Mixed flocks of corvids including Ravens were recorded twice. On 16 February 2003, the flock of 35 Ravens and 8 Hooded Crows (Corvus cornix) and on 15 March 2003, the flock of 180 Jackdaws (Corvus monedula), 60 Ravens and 10 Rooks (Corvus frugilegus) were recorded. The latter was the biggest concentration of Ravens ever recorded during present study.

\section{DISCUSSION}

Mean density of Ravens recorded in this study was relatively high in comparison with densities recorded elsewhere. However, it was characterized by strong changes within individual period. During winter the mean density of the Raven in central- 
eastern Poland was 1.08 indiv. / $10 \mathrm{~km}$ (Jędrzejewski 2000) and in the Bieszczady mountains 10.7-13.8 indiv. / $10 \mathrm{~km}$ (Zbrożek 2001).

Table 2

Flock size of the Raven during subsequent periods in the Orawa - Nowy Targ Basin in the 2002/2003-2004/2005 non-breeding seasons ( $N$ - number of groups)

\begin{tabular}{|c|c|c|c|c|c|c|c|c|}
\hline \multirow{2}{*}{ Group size } & \multicolumn{2}{|c|}{ Autumn } & \multicolumn{2}{|c|}{ Early winter } & \multicolumn{2}{|c|}{ Winter } & \multicolumn{2}{|c|}{ Early spring } \\
\hline & $N$ & $\%$ & $N$ & $\%$ & $N$ & $\%$ & $N$ & $\%$ \\
\hline 1 & 22 & 44.0 & 18 & 52.9 & 42 & 38.9 & 9 & 45.0 \\
\hline 2 & 15 & 30.0 & 10 & 29.4 & 43 & 39.8 & 6 & 30.0 \\
\hline $3-5$ & 8 & 16.0 & 3 & 8.8 & 16 & 14.8 & 2 & 10.0 \\
\hline $6-15$ & 4 & 8.0 & 2 & 5.9 & 5 & 4.6 & 2 & 10.0 \\
\hline $16-50$ & 1 & 2.0 & 1 & 2.9 & 2 & 1.9 & 1 & 5.0 \\
\hline Total & 50 & 100 & 34 & 100 & 108 & 100 & 20 & 100 \\
\hline Mean flock size & \multicolumn{2}{|c|}{3.0} & \multicolumn{2}{|c|}{2.5} & \multicolumn{2}{|c|}{2.9} & \multicolumn{2}{|c|}{4.0} \\
\hline
\end{tabular}

Despite numerous occurrence of other corvids in the Orawa - Nowy Targ Basin (Ciach et al. 2006), their mixed flocks with Ravens were recorded exceptionally. Records of single Ravens or groups of two birds, probably family pairs, dominated. Records of flocks were considerably less frequent, however they include major number of birds present in a given area. Density of single individuals and groups of two birds was twofold lower than mean density of all recorded types of groups and was characterized by minor fluctuations. Probably it was similar to breeding density of Ravens in a given area.

Influx of nomadic birds from neighbouring grounds probably strongly affects non-breeding density of the Raven in the Orawa - Nowy Targ Basin. It results from the presence of carrion, which is the basic food of Ravens during non-breeding season (Zawadzka 1996). Its irregular and temporal accessibility (in the form of preys of large carnivores, animals dead due to harsh weather conditions, as well as animal carcasses dumps) led to the occurrence of local concentration of Ravens, which influenced considerably the abundance fluctuations. Frequency of foraging on carrion and size of flocks increase in winter (Rösner et al. 2005). Changes in food supply within the Orawa - Nowy Targ Basin probably contribute to nomadic movements of local population as well as to influxes of birds from neighbouring areas. Birds in search for food may cover a few thousand kilometres (Heinrich et al. 1994). It has been shown for the Bieszczady mountains (SE Poland) that in the areas abundant in carrion, higher density of Ravens occurred (Zbrożek 2001). It is possibly linked to the presence of wolves (Canis lupus) and actually of their prey remains in this region. Accessibility of carrion led to natural, local and short-term foraging concentration, which caused an increase of mean density. 


\section{ACKNOWLEDGEMENTS}

We wish to express our gratitude to the members of the Ornithological Section of the Foresters' Scientific Club of the Faculty of Forestry of the Agriculture University of Kraków for their help in the fieldwork. Particularly we wish to thank Marta Bylicka, Marcin Stańczyk, Michał Mężyk, Marzena Barczyk, Paweł Dec and Bartosz Kwarciany. We want to thank Bożena Kalejta-Summers sincerely for critical comments on the first draft of this paper and for helping us to improve English.

\section{REFERENCES}

Bednorz J. 2000. Corvus corax L., 1758 - kruk. In: Bednorz J., Kupczyk M., Kuźniak S., Winiecki A. 2000. Ptaki Wielkopolski. Monografia faunistyczna. Bogucki Wyd. Nauk., Poznań: pp. 513-515.

Bednorz J. 2005. Current knowledge about the Raven Corvus corax in Poland. In: Jerzak L., Kavanagh B., Tryjanowski P. (Eds). 2005. Corvids of Poland. Bogucki Wyd. Nauk., Poznań: pp. 127-135.

Betleja J., Meissner W. 2005. Occurrence of corvids Corvidae on rubbish-dumps in Poland in 2002-2004. In: Jerzak L., Kavanagh B., Tryjanowski P. (Eds). 2005. Corvids of Poland. Bogucki Wyd. Nauk., Poznań: pp. 207-214.

Busse P. 1969. Results of ringing of European Corvidae. Acta orn. 11, 8: 263-328.

Ciach M., Wikar D., Bylicka M. 2006. Birds community of open habitats of Kotlina Orawsko-Nowotarska valley in non-breeding season. Berkut 15: 55-65.

Heinrich B., Kaye D., Knight T., Schaumburg K. 1994. Dispersal and association among Common Ravens. Condor 96: 545-551.

Jędrzejewski M. 2000. Zimowanie ptaków lądowych $w$ dolinach wybranych rzek środkowo-wschodniej Polski $w$ dekadzie 1984-1993. Kulon 5: 3-37.

Jermaczek A., Czwałga T., Jermaczek D., Krzyśków T., Rudawski W., Stańko R. 1995. Ptaki Ziemi Lubuskiej. Monografia faunistyczna. Wyd. Lubuskiego Klubu Przyrodników, Świebodzin.

Konček M. (Ed.). 1974. Klima Tatier. Vyd. Slovenkoj Akad. Vied, Bratislava.

Kondracki J. 1998. Geografia regionalna Polski. PWN, Warszawa.

Mošanský L., Karaska D. 2002. The Raven (Corvus corax). In: Danko Š., Darolová A., Krištín A. (Eds). 2002. Birds distribution in Slovakia. VEDA, Bratislava: pp. 587-589.

Rösner S., Selva N., Müller T., Pugacewicz E., Laudet F. 2005. Raven Corvus corax ecology in a primeval temperate forest. In: Jerzak L., Kavanagh B., Tryjanowski P. (Eds). Corvids of Poland. Bogucki Wyd. Nauk., Poznań: pp. 385-405.

Tomiałojć L., Stawarczyk T. 2003. Awifauna Polski. Rozmieszczenie, liczebność i zmiany. PTPP "pro Natura", Wrocław.

Zawadzka D. 1996. Distribution, habitat selection, food and reproduction of the Raven (Corvus corax) in the National Park of Lake Wigry. Not. Orn. 37: 225-244.

Zbrożek A. 2001. Zimowe rozmieszczenie $i$ wahania liczebności kruka Corvus corax w Bieszczadach. Ptaki Podkarpacia 9: 5-15. 